\title{
OS CAPSAD, AS COMUNIDADES TERAPÊUTICAS E O “USUÁRIO DE DROGAS": POLÊMICASE PARADOXOS
}

\author{
Elisson Alexandre Ferreira César ${ }^{1}$ \\ Luzania Barreto Rodrigues ${ }^{2}$
}

Resumo: 0 trabalho ora proposto reflete sobre dados empíricos provenientes de três campos de investigação: 1) o Centro de Atenção Psicossocial Álcool e outras Drogas (CAPSad); 2) uma comunidade terapêutica de cunho evangélico; e 3) o Coletivo Ciranda de Rua de Redução de Danos, dispositivos de atenção e cuidado dispensados a usuários de substâncias psicoativas (SPA). Utilizando-se de algumas técnicas importantes ao trabalho etnográfico, como a observação participante, as conversas informais e as entrevistas gravadas, pôde-se aceder a questões que explicitam controvérsias quanto à prática da Política Nacional direcionada a este público específico, bem como desvela debates polêmicos sobre a incidência de padrões morais e normas de conduta no tratamento aí implicado, além de ser privilegiado o uso de fármacos em detrimento de outras medidas terapêuticas. Diante disso, atentamos para a necessidade premente de políticas eficazes de assistência social em consonância com uma assistência de saúde que possa contemplar as múltiplas dimensões que abarca o fenômeno estudado, seja em espaços institucionalizados ou em territórios de consumo.

Palavras-Chave: Etnografia, Usuário de drogas, Paradoxos terapêuticos.

Abstract: The work proposed here reflects on empirical data from three research fields: 1) Centro de Atenção Psicossocial Álcool e outras Drogas (CAPSad) 2) a therapeutic community of evangelical nature, and 3) Coletivo CIRANDA de Rua de Redução de Danos, attention and care devices offered to users of psychoactive substances (SPA). Using some important techniques to ethnographic work, as participant observation, informal conversations and recorded interviews, it was allowed to access issues that explain controversies regarding the practice of the National Politics targeted to this specific audience, as well as unveil controversial debates on the incidence of moral standards and rules of conduct in the treatment within, and moreover the prevalence of drug use over other therapeutic measures. Therefore, we pay attention to the urgent need for effective social policies in line with health

1 Bolsista de Iniciação Científica (CNPq); graduando em Ciências Sociais; pesquisador do Laboratório de Pesquisa Interdisciplinar sobre Substâncias Psicoativas, da Universidade Federal do Vale do São Francisco (LAPIS/UNIVASF). Endereço eletrônico: elisson.cezar@ hotmail.com.

2 Doutora em Ciências Sociais pela UFBA; Pós-Doutora pela Faculdade de Medicina da Bahia (FAMEB/UFBA), com bolsa FAPESB; Professora Adjunta III de Antropologia, no Colegiado de Ciências Sociais da UNIVASF; docente da Especialização em Educação no Campo; Coordenadora do LAPIS. Endereço eletrônico: luzania.rodrigues@ig.com.br. 
care that can address the multiple dimensions encompassing the phenomenon, either in institutionalized places or consumers' territories.

Keywords: Ethnograthy, Drugs user, Therapeutical paradoxes.

\section{INTRODUÇÃO}

Neste artigo, o objetivo é refletir acerca das polêmicas e paradoxos que cercam a implementação do CAPSad - Centro de Atenção Psicossocial Álcool e outras Drogas da Cidade de Juazeiro, no Norte da Bahia, levando em conta as práticas e concepções dos denominados "usuários de drogas" alcançados, ou não, por sua ação, no período de agosto de 2010 a abril de 2012.

Os dados empíricos que embasam a presente reflexão são provenientes da pesquisa intitulada M odalidades e estratégias de ação dos profissionais do CAPSad/Juazeiro (BA) e sua recepção por parte dos usuários ${ }^{3}$ do Serviço e do trabalho de extensão desenvolvido, nas ruas desta cidade e numa Comunidade Terapêutica, por estudantes de psicologia da UNIVASF - Universidade Federal do Vale do São Francisco, que compõem a Ciranda de Rua - Coletivo de Redução de Danos, orientado por Luzania Barreto Rodrigues e vinculado ao Laboratório de Pesquisa Interdisciplinar sobre 0 Uso de Substâncias Psicoativas - LAPIS/Colegiado de Ciências Sociais/UNIVASF.

Durante a realização da pesquisa supracitada, as ações dos profissionais do CAPS ad/Juazeiro - como os primeiros contatos com os usuários de drogas e sua recepção inicial - foram perscrutados por meio de algumas técnicas utilizadas no trabalho de campo, para a produção de etnografias, como a observação participante, as conversas informais e entrevistas; procedimentos realizados com os profissionais da instituição e com os usuários de drogas, os quais constituíram importantes instrumentos para levantamento de tais dados. As entrevistas foram precedidas por um período de dois meses de observação participante e conversas informais, técnicas através das quais pudemos levantar dados que vieram subsidiar um qualificado roteiro de entrevistas.

No trabalho desenvolvido pelos membros da Ciranda de Rua, a observação participante constitui, também, importante instrumento metodo-

3 O termo usuário - introduzido pela legislação do SUS (Leis 8.080/90 e 8.142/90) - conotaria um sujeito ativo em oposição à noção de paciente, entendido como sujeito passivo e alienado do conhecimento dos seus direitos.

210 Número temático: Metodologias de pesquisa em ciências sociais e humanas. A Cor das Letras 
lógico, mediante o qual os estudantes extensionistas constroem vínculos com a comunidade e acedem ao cotidiano e à cultura dos atores sociais que estão envolvidos no contexto local. Para isso, há uma contínua articulação com informantes-chave, identificados através de conversas informais.

Uma vez identificados os informantes-chave, estes são convidados a atuar como guias de trabalho de campo, auxiliando na identificação não apenas dos "usuários de drogas", mas dos seus locais de encontro, sociabilidade e consumo de tais substâncias. Sendo assim, os contatos com os "usuários de drogas" são muito importantes para o levantamento de dados relativos ao consumo de substâncias psicoativas, seus contextos e modalidades de uso, graus de cuidado com a saúde, bem como para a construção conjunta de Estratégias de Redução de Danos junto aos usuários. A partir de então, os estudantes passam a implementar ações contextualizadas com vistas à promoção da saúde dos "usuários de drogas", nos seus locais de consumo, circulação e moradia. Dentre estas ações, pode-se destacar a distribuição de preservativos masculinos e femininos, protetor labial com propriedades umectante e anti-inflamatória - uma vez que para fumar crack é necessário fazê-lo entrar em combustão, a qual, via de regra, queima os lábios do fumante desta substância -, distribuição de pequenos retalhos de tecido de algodão, a serem acoplados na extremidade do cachimbo por onde a fumaça é sugada, a fim de proteger suas vias respiratórias dos resíduos tóxicos resultantes da combustão.

Outro contexto de atuação dos extensionistas é uma Comunidade Terapêutica (CT), localizada no limite entre a zona rural e a periferia geográfica e social da Cidade de Juazeiro. Esta CT destina-se ao tratamento de pessoas do sexo masculino, a partir dos 18 anos de idade. De orientação evangélica, esta instituição baseia-se no princípio de que indivíduos "dependentes de drogas" encontram-se doentes e guiados pelo demônio. Portanto, sua cura só será alcançada mediante a abstinência do consumo de drogas e à conversão religiosa. As pessoas lá internadas, os denominados "alunos", devem permanecer em tratamento durante nove meses, tempo de "gestação de uma nova vida", numa clara alusão ao renascimento, ou ressurreição, para uma vida virtuosa. Não obstante, poucos alcançam esse objetivo, pois, a exigência da abstinência imediata de substâncias psicoativas, 0 isolamento social e os constantes problemas com seus superiores hierárquicos diretos, os denominados "obreiros", resultam em evasão e rotatividade. 


\section{A EMERGÊNCIA DO CAPSAD}

Os Centros de Atenção Psicossocial Álcool e outras Drogas foram criados em 2002, como unidades de referência destinadas ao tratamento de pacientes cujo principal problema de saúde é o uso prejudicial de álcool e/ou outras substâncias psicoativas (SPA). Os CAPSad fazem parte do Sistema Único de Saúde - SUS, integrando uma rede mais ampla de assistência à saúde mental e que fora forjada nos meandros da Reforma Psiquiátri$\mathrm{ca}^{4}$.

Esta Reforma é uma proposta que atende à necessidade de mudanças estruturais e ideológicas no tratamento dispensado a pacientes com sofrimento mental, reivindicada por profissionais de saúde de distintas especialidades. Preconiza-se a inversão de sistemas fechados, como os manicômios, para unidades de funcionamento flexível, com atendimento extra-hospitalar, além da participação de uma equipe multiprofissional e a possibilidade do usuário deste serviço não perder os vínculos sociais que mantém, tendo em vista que propõe um tratamento integral. Seu funcionamento é diurno e se dá de segunda às sextas-feiras.

Destarte, o CAPSad, enquanto instituição de atenção a usuários de álcool e outras drogas, deveria articular-se diretamente à Política de Saúde Mental do M inistério da Saúde, enquadrando-se numa perspectiva intersetorial, ao contemplar uma rede assistencial para este público-alvo específico, pois objetiva uma associação com Hospitais Gerais, Prontos Socorros, Estratégias de Saúde da Família e demais unidades básicas de saúde, Comunidades Terapêuticas, Instituições de Defesa dos Direitos do Usuário, além das múltiplas instituições sociais existentes e que se implicam com as questões aí assentadas.

0 CAPSad constitui-se, assim, como um dispositivo de funcionamento ambulatorial, com o propósito de estabelecer um trabalho multidisciplinar e marcado por práticas integrais de atenção aos usuários de álcool e outras drogas, contemplando a efetiva inserção destes na comunidade e na família, além da prevenção e cuidado contra a estigmatização de tais sujeitos. De tal modo, as ações no interior do CAPSad devem ser pautadas por uma relação dialógica entre este dispositivo de saúde e a comunidade, dedicando-se, não obstante, ao exercício da interdisciplinaridade no que concerne

\footnotetext{
4 Para uma análise mais minuciosa da Reforma Psiquiátrica Brasileira, ver AM ARANTE, 2010.

212 Número temático: Metodologias de pesquisa em ciências sociais e humanas. A Cor das Letras 
às áreas profissionais de intervenção, bem como aos princípios da Política de Redução de Danos.

Em linhas gerais, a Redução de Danos é um entendimento alternativo atinente às estratégias tradicionalmente utilizadas no tratamento de "usuários de drogas" - que elegem a abstinência como caminho único e, ou, que, num viés puritano, demonizam as substâncias psicoativas e seus consumidores -, sejam estas lícitas ou ilícitas. As práticas de Redução de Danos não concorrem, necessariamente, com os pressupostos da abstinência; inclusive, pode se tornar, de maneira processual, um passo para que o sujeito construa novos arranjos de sociabilidade que não pressuponham 0 consumo de determinadas substâncias. Trata-se da minimização de problemas de saúde associados ao uso/abuso de drogas, sem que ocorra um rompimento abrupto do consumo, pois há uma compreensão de que este fenômeno expressa a relação que é estabelecida entre um sujeito, uma dada substância psicoativa e um contexto social. Tal complexidade do fenômeno requer pensar 0 assunto atentando para as suas distintas dimensões, isto é, deslocando o foco de medidas reducionistas e passando a atentar para as especificidades do universo simbólico dos usuários abusivos de SPA - aí entendidas como posição de classe, gênero, escolaridade, idade, origem social, círculos de relações interpessoais, etc.

Entretanto, vale ressaltar que "redução de danos" não é um conceito consensual na bibliografia sobre o tema, tampouco entre aqueles que praticam. De acordo com Tarcísio Andrade, constituem ações que objetivam minimizar danos biológicos, psicossociais e econômicos decorrente do uso ou abuso de drogas, sem sequer exigir a redução do consumo das substâncias psicoativas. Trata-se de ações orientadas por três princípios norteadores: pragmatismo, tolerância e diversidade (ANDRADE, 2004, p. 87).

\section{CAPSAD DE JUAZEIRO, BAHIA}

O CAPSad de Juazeiro-BA, como supracitado, foi um dos campos de investigação e está situado no Bairro Pedra do Lord, situado em área periférica do referido município. Sua fundação deu-se em março de 2005. A instituição foi contemplada com um espaço de aproximadamente $10.000 \mathrm{~m}^{2} \mathrm{e}$ comporta um estacionamento para funcionários, usuários do serviço e possíveis visitantes, além de outros três espaços bem delimitados que compõem a sua estrutura física. No primeiro, funcionam as salas para os diversos atendimentos realizados na unidade. Possui a recepção, em que se dá a marcação de consultas e retornos, bem como a prestação de informações e 
solicitações gerais; a sala de arquivos, onde são colocados os prontuários e demais documentos referentes aos usuários; a sala de coordenação; as salas de atendimento médico, psicológico, de assistência social e de trabaIhos pedagógicos; 0 ambulatório, destinado à desintoxicação de consumidores abusivos de drogas, que se encontrem impregnados; a enfermaria, onde são administrados os medicamentos recomendados pelo psiquiatra responsável; cinco banheiros; além de outras salas que foram destinadas à biblioteca, depósito de alimentos, produtos de limpeza e equipamentos de manutenção. No segundo espaço, estão dispostos a cozinha, onde é preparada as duas refeições diária; o refeitório, com mesas e cadeiras para aproximadamente 15 pessoas; três salas destinadas à realização de oficinas, atualmente em funcionamento apenas uma (artesanato); duas salas para repouso, e mais quatro banheiros. 0 terceiro espaço, por assim dizer, é 0 restante do terreno da instituição, em que os usuários podem cultivar frutas, grãos e hortaliças, e onde há um campo de futebol improvisado

\section{NOVAS CONCEPÇÕES E PRÁTICAS}

Os momentos de mudanças paradigmáticas, como o da Reforma Psiquiátrica - movimento de oposição às instituições manicomiais no Brasil, iniciado em 1.978 (CARVALHO, 2013), e ainda em curso -, fazem eclodir muitas polêmicas e paradoxos.

Como pudemos observar durante os períodos de pesquisa e extensão, a implementação desta política esbarra na falta de entendimento e afinidade da maioria dos profissionais de saúde e assistência social no que concerne aos princípios e estratégias de Redução de Danos (RD) e na resistência frente ao trabalho em equipe. Vemos-nos frente a fenômenos de tradição, da força de uma cultura medicalizada (FOUCAULT, 2001), de uma coletividade fortemente marcada pela certeza de que "o drogado" é um "doente" e, ou, um "marginal". Famílias e profissionais de saúde retroalimentam tais noções ao vivenciarem, no cotidiano, a difícil tarefa de lidar com comportamentos mais, ou menos, compulsivos. A urgência de expurgar a "doença" e o "marginal" alimenta profundamente a crença na abstinência e na necessidade do isolamento.

Certamente por esta razão, grande parte da procura ao serviço se dá com o acompanhamento de familiares do usuário de Substâncias Psicoativas (SPA), sobretudo pai, mãe, tios e/ou irmãos, que apontam problemas relacionados ao uso ou abuso de SPA. A maioria dos usuários teve acesso a 
este serviço de saúde levada por familiares que apontam a incidência de agressividade em casa, falta de um relacionamento amistoso com a família (pais, companheiros, filhos, etc.), perda de emprego em função do uso indevido de SPA, problemas de saúde e, em menores proporções, há o relato de pequenos furtos e roubos para o custeio do consumo, além do envolvimento com o tráfico de drogas e outras situações que envolvem risco. Por outro lado, alguns usuários relatam que não percebem problemas em relação ao consumo, mas a família almeja sua abstinência por razões morais e por não identificar naquele sujeito, sob o efeito de SPA, o filho, irmão, etc., que tinha antes de iniciar o uso; acredita que, ao utilizar uma substância psicoativa, o seu familiar não se encontra em condições "normais".

As práticas dos profissionais de saúde, por sua vez, aparentam ser marcadamente vigilantes, punitivas e normatizadoras (cf. FOUCAULT, 2004), como identificadas, por exemplo, nas sessões de acolhimento, realizadas coletivamente às segundas-feiras. Algumas contradições se expressam nessas ações, pois, tendo como referência as recomendações do M inistério da Saúde ${ }^{5}$ sobre os cuidados que devem ser ofertados ao usuário do referido serviço, indica-se um trabalho educativo/preventivo contra o estigma e o preconceito relativos ao uso de substâncias psicoativas; 0 desenvolvimento de estratégias que promovam a inserção efetiva dos usuários em espaços de sociabilidade; além de possibilitar um acolhimento qualificado e a promoção de cuidados personalizados, contemplando, assim, as particularidades de cada sujeito, sem que este, absolutamente, seja exposto a qualquer situação sob a qual se sinta constrangido ou passível de ser classificado em categorias homogeneizadoras.

Assim, na contramão da Política de Redução de Danos e das Estratégias de Redução de Danos (ERD), pudemos testemunhar localmente, às segundas-feiras, que profissionais do CAPSad/Juazeiro-Ba fazem da "sessão de acolhimento" em grupo um momento de averiguação tanto da abstinência quanto dos fatores que, no seu entender, possam garanti-la: isolamento em casa, nos finais de semana, distanciamento dos amigos e repressão ao consumo moderado, aí entendidos como recaídas.

As relações estabelecidas entre paciente/profissional ocorrem com interações que variam de acordo com o profissional, pois não há afinidade por parte dos pacientes em relação a todos os profissionais, uma vez que

5 Para mais informações sobre abordagens terapêuticas dispensadas a usuários de SPA no Sistema Único de Saúde (SUS), ver Portal do Ministério da Saúde: http://portal.saude. gov.br/portal/arquivos/pdf/abordagemsus.pdf. 
alguns deles não mantêm contato externo ao setting terapêutico. Destacase maior afinidade com a enfermeira chefe (coordenadora da unidade), a cozinheira e a oficineira, por se manterem sempre solícitas a conversar e manter um contato direto com os usuários.

Essa falta de contato com os demais profissionais revela, nas descrições dos próprios usuários, a necessidade de intervenções individualizadas, por parte das áreas de psiquiatria, psicologia e pedagogia, além de grupos de discussão sobre os problemas enfrentados pelos usuários, o que até acontece, mas que se resumem ao uso e abuso de drogas, isto é, não contemplam as dimensões mais amplas suas vidas. Ademais, o que se pode notar é o saber médico figurando como recurso terapêutico central na resolução de qualquer problema de saúde, relegando às demais alternativas de cuidado um lugar secundário e de eficácia impensada. Daí a grande aceitação com relação ao tratamento oferecido pelo serviço, no que se refere ao uso dos medicamentos e à frequência na instituição, no entanto, percebese, na maioria dos casos, a continuidade do uso/abuso das substâncias consumidas antes de iniciar o tratamento.

A centralidade do uso de medicamentos ${ }^{6}$ é reproduzida nos discursos e nas práticas dos usuários do CAPSad. Afinal, é o que eles têm de concreto e contínuo no tratamento recebido na instituição. Tais sujeitos sociais concebem os medicamentos como um procedimento eficaz e importante, pois, segundo o seu conhecimento, repassado pelos profissionais, são substâncias que ajudam nos sintomas de crise de abstinência e desintoxicam o organismo das outras substâncias consumidas por eles, fazendo com que cesse a vontade de usá-las. Dizem não ter sintomas adversos pelo consumo destes medicamentos, apenas uma sonolência que não é natural.

A par disso, ressentem-se da falta de atividades terapêuticas - lúdicas, artesanais ou laborais - que ocupem o tempo em que estão no interior da instituição e que possibilitem novas perspectivas para os pacientes, indicando que não há uma quadra de esportes, sala de informática, cursos e oficinas. Reclamam da infraestrutura em função de não ter camas e nem armários para guardar objetos pessoais e muitos resumem a estadia no CAPS ad/Juazeiro-BA em consumir medicamentos, comer, dormir, acordar

6 De acordo com Maurício Fiore, "uma sociedade medicalizada [...] não é necessariamente aquela em que os médicos e suas prescrições impõem seu poder, na condição de sujeitos, sobre cidadãos leigos sujeitados: trata-se de uma sociabilidade em que os dilemas colocados pelos saberes médicos são compartilhados enquanto valores fundamentais e perseguidos continuamente" (FIORE, 2008, p. 143).

216 Número temático: Metodologias de pesquisa em ciências sociais e humanas. A Cor das Letras - UEFS, n. 14, 2013 
para comer e dormir novamente. A continuidade do tratamento fora da instituição se dá com o uso dos medicamentos e com a reprodução do discurso de adesão às recomendações dos profissionais de manter-se afastado dos locais de uso, além de evitar o primeiro contato com as SPA, pois depois deste primeiro contato é que os usuários seriam induzidos ao consumo exacerbado, indicações que, contraditoriamente, eles afirmam procurar seguir à risca, ao passo em que relatam a continuidade do uso de SPA e o acesso a novas substâncias desta natureza.

No entanto, o público-alvo que frequenta o CAPSad/Juazeiro não é homogêneo. 0 que verificamos é que uma parcela deste público adere a tais recomendações, notadamente os denominados usuários de álcool, que, via de regra, optam pela abstinência desta substância. Outra parcela limitase aos cuidados com a higiene corporal, a alimentação e ao repouso, nos colchões dispostos no chão dos quartos da instituiçãa, onde são atendidos das oito horas da manhã às três horas da tarde. A partir deste horário, esta parcela de usuários costuma passar grande parte do seu tempo consumindo distintas substâncias psicoativas, como álcool, maconha, cocaína, crack, LSD, anfetamina, chá de cogumelo, zabumba e lírio. A tal variedade de substâncias psicoativas muitos usuários passam a ter acesso e mesmo conhecimento mediante a sociabilidade com os demais usuários do serviço, com os quais interagem e dialogam durante longas horas de ociosidade na instituição.

Outro ponto muito importante é o significado e o motivo de estar sendo tratado no CAPS ad para cada usuário. Uns estão pagando pena, por determinação judicial; alguns estão afastados do trabalho por incapacidade decorrente do uso de substâncias psicoativas, principalmente álcool; outros por iniciativa própria ou familiar. Há ainda os que dizem estar no CAPSad por uma missão divina, e este é um ponto curioso, uma vez que, teoricamente, os CAPS ad constituiriam espaço laico.

Neste sentido, um dos pacientes declarou estar em tratamento no CAPSad/Juazeiro não por necessitá-lo, pois já estaria "curado das drogas", mas, sim, para garantir a eficácia do tratamento dos demais, pois considera que o que é oferecido pelo serviço não é suficiente. Ademais, afirmou estar preparando outros "irmãos" lá dentro para ocuparem o seu lugar de evangelizador. 0 discurso religioso é muito presente na fala de alguns pacientes do CAPSad/J uazeiro, inclusive, no grupo de informantes privilegiados. Muitos constroem esses discursos em Comunidades Terapêuticas religiosas e expressam a vontade de voltar a uma dessas casas, o que não fazem por 
falta de recursos financeiros, pois, nelas, o internamento dá-se mediante 0 pagamento de mensalidades.

0 vaivém entre instituições laicas e religiosas de tratamento parece uma constante entre pessoas que fazem uso abusivo de SPA. Para aqueles que se encontram radicados nas ruas de Juazeiro, decidir entre umas e outras constitui dilema constante. Isto é, entre este último segmento, o Redutores de Danos da Ciranda de Rua - Coletivo de Redução de Danos, que atuam nas ruas da cidade de Juazeiro, encontram resistência por parte do público-alvo, cujo argumento mais frequente reside na lógica antimanicomial do CAPSad. Isto é, como esta instituição não comporta o internamento/isolamento da vida social, seus usuários argumentam sentirem-se desprotegidos, pois são impelidos a retornar para o ambiente de consumo de SPA, por não ter outro lugar pra ir, e ter contato com as mesmas pessoas. Inversamente, nas CTs-Comunidades Terapêuticas (leia-se casas de recuperação de orientação evangélica, localizadas, via de regra, em zonas periféricas ou rurais) estariam protegidos das variáveis que, em tese, os compelem ao consumo. Sendo assim, este segmento parece aderir, ao menos parcialmente, à lógica manicomial, hospitalocêntrica e puritana.

A meio caminho entre estes dois extremos, registramos que em uma Comunidade Terapêutica, onde seis "Cirandeiros", que se encontram no estágio profissional em Psicologia, oferecem atendimento individual e em grupo, são identificados internos que já fizeram tratamento no CAPSad, sendo que ainda o frequentam na qualidade de pacientes não-intensivos, isto é, são atendidos pelo médico psiquiatra, mensalmente, e usam a medicação prescrita, com regularidade. Estariam, aí, posicionados no limite entre uma instituição total ${ }^{7}$ - onde dormem, banham-se, alimentam-se, participam de rituais religiosos, executam tarefas laborais demandadas, jogam futebol nos finais de semana e são exortados a abdicar de manter intercursos sexuais - e os benefícios da medicação psiquiátrica.

Em contrapartida, num dos lócus de observação, uma feira-livre da cidade, há um grupo de aproximadamente dez homens de meia-idade, que tiveram uma experiência considerada muito negativa, em uma CT localizada na Região Metropolitana de Salvador, na qual recebiam alimentação de baixa qualidade e de sabor ruim, além de terem que trabalhar na lavoura sem remuneração. Ademais, eram obrigados a orar, de joelhos, durante três horas por dia, o que Ihes causava hematomas. Por fim, quem tentasse

7 Ver GOFFM AN (1974).

218 Número temático: M etodologias de pesquisa em ciências sociais e humanas. A Cor das Letras - UEFS, n. 14, 2013 
fugir, era perseguido por homens armados de revólver. Por outro lado, este mesmo grupo negava-se a submeter-se a tratamento no CAPSad, alegando a distância física da instituição e a sua aversão a medicamentos psiquiátricos, ao que retrucavam: "eu não sou doido, não, dona".

\section{BREVES CONSIDERAÇÕES FINAIS}

Manter-se no CAPSad ou em Comunidades Terapêuticas aumenta o ganho de capital simbólico, por parte dos usuários destes serviços, uma vez que se percebem como pessoas que precisam readquirir a confiança e a boa imagem nos círculos sociais mais próximos - de familiares, amigos e vizinhos. Portanto, tais instituições acabam por representar espaços terapêuticos legítimos que possibilitam o retorno de suas melhores virtudes, em contraposição ao "vício", isto é, ao consumo abusivo de SPA.

Ao perscrutar os dados empíricos coletados a partir da observação nestas duas instituições, o que se pode perceber é uma acentuada rotatividade das pessoas que iniciam o tratamento, mediante abandono, suspensão ou expulsão. Diante deste quadro, cabe indagar quais as principais variáveis que concorrem para o fenômeno. De saída, parece imperativo admitir que as práticas e concepções do público-alvo, na contramão dos agentes sociais que oferecem assistência laica ou religiosa à saúde, não ratificam a antinomia laico/religioso, mas parecem sustentar a sua complementaridade.

No que tange às ações do Coletivo de Redução de Danos - Ciranda de Rua surge da necessidade de transpor os muros da universidade e estender as querelas assentadas sobre a referida temática, a outros campos de atuação. Mais que isso, propõe-se a inverter a lógica institucionalizada sob a qual estão dispostas as unidades de saúde, encaminhando-se até 0 usuário de substâncias psicoativas, nos seus respectivos locais de estadia e concomitantemente de consumo cotidiano, para que sejam elaboradas, a partir das especificidades de cada grupo e de cada usuário, ações de cuidado à saúde relacionados aos problemas decorrentes do uso e/ou abuso de "drogas". Não obstante, compreende-se que o Coletivo pode se constituir em um dos dispositivos de conformação de uma rede mais ampla e colaborativa de saúde, estabelecendo parcerias com as outras instituições.

Ademais, referenciando-se em qualquer um dos pólos investigados, 0 que se pode notar é a necessidade premente de políticas eficazes de assistência social, complementares a assistência de saúde. Contudo, é preciso considerar que as pessoas são donas dos seus corpos e destinos, o que nos 
faz crer que causar danos a si próprio, ou consumir-se, é um direito que Ihes assiste e no qual insistem. Sem dúvida, a exposição de corpos maltrapiIhos, sujos e entorpecidos faz lembrar aos socialmente incluídos que a linha imaginária que os separam é muito tênue. Talvez por isto estes Outros sejam temidos.

\section{REFERÊNCIAS}

ADÚN, G. A solidão de Soledade. In: RIBEIRO, Esmeralda; BARBOSA, Márcio. (Org.). Cadernos Negros, v. 34. São Paulo: Quilombhoje, 2011, p. 99-106.

AM ARANTE, P. D. de C. 30 anos da reforma psiquiátrica brasileira. In: FONTES, B. A. S. M.; FONTE, E. M. M. da. Desinstitucionalização, redes sociais e saúde mental: análise de experiências da reforma psiquiátrica em Angola, Brasil e Portugal. Recife: Ed. Universitária da UFPE, 2010.

ANDRADE, T. M. Redução de danos: um novo paradigma? In: TAVARES, L. A. et al. Drogas: tempo, lugares e olhares sobre seu consumo. Salvador: EDUFBA; CETAD/UFBA, 2004.

BRASIL. Abordagens terapêuticas a usuários de cocaína/crack no Sistema Único de Saúde. M inistério da Saúde. Braślia, abr. 2010.

CARVALHO, J. C. A produção de leis e normas sobre drogas no Brasil: a governamentabilidade da criminalização. Disponível em: www.neip. info. Acesso em: 25 fev. 2013.

FIORE, M. Prazer e risco: uma discussão a respeito dos saberes médicos sobre o uso de "drogas". In: LABATE, B. C. et al. (Org.). Drogas e cultura: novas perspectivas. Salvador: EDUFBA, 2008.

FOUCAULT, M. História da sexualidade I: a vontade de saber. Rio de Janeiro: Graal, 2001.

FOUCAULT, M. 0 nascimento da clínica. São Paulo: Forense Universitária, 2004.

GOFFM AN, E. Manicômios, prisões e conventos. São Paulo: Perspectiva, 1974. 